Pacific Journal of Mathematics

EVALUATION OF AN INTEGRAL OCCURRING IN 


\title{
EVALUATION OF AN INTEGRAL OCCURRING IN SERVOMECHANISM THEORY
}

\author{
W. A. MERSMAN
}

1. Introduction. In the study of dynamical systems in general, and servomechanisms in particular, it is often required to determine the (constant) coefficients in a linear, ordinary, differential equation in such a way as to minimize an integral involving the square of the difference between the solution of the equation and a known function. The latter may be given in either analytical or numerical form. In the design of a servomechanism the known function is the "input"; the solution of the equation is the "output"; and the coefficients of the equation are the circuit constants to be determined. $A$ similar problem arises in the study of aircraft flight records, in which the known function is any of the dynamic variables used to describe the motion, and the coefficients are the socalled aerodynamic derivatives, the determination of which is the purpose of the flight.

Mathematically similar problems also arise in the analysis of a mixture of radioactive substances or of bacteria. The known function is, say, the total weight of the mixture as a function of time, and the unknown coefficients are the relative weights of the different substances initially present.

All such problems can be solved by the method of least squares, and the procedure always leads, at a certain stage, to the evaluation of an integral of a particular type. This integral has been studied by R. S. Phillips [3, Chap. 7, $\$ 7.9]$, who has given a procedure for its evaluation and a short table of results. The purpose of the present note is to derive a simple, explicit formula for this integral.

2, Evaluation of the integral. The integral to be evaluated is

$$
I=\frac{1}{2 \pi i} \int_{-\infty i}^{\infty i} \frac{g(x)}{h(x) h(-x)} d x
$$

where

Received March 8, 1951, and in revised form April 12, 1952.

Pacific J. Math. 3 (1953), 627-632 


$$
\begin{aligned}
i & =\sqrt{i-1}, \\
g(x) & =\sum_{k=1}^{n} g_{k} x^{2(n-k)}, \\
h(x) & =\sum_{k=0}^{n} a_{k} x^{n-k}, a_{k} \text { real, } a_{0} \neq 0 .
\end{aligned}
$$

There is no loss of generality in restricting $g(x)$ to contain only even powers, since odd powers would make no contribution to the value of the integral. It is assumed that the zeros of $h(x)$ are all distinct and have their real parts negative. Then the integration can be performed immediately by means of the theory of residues [4, Chap. 6], and the result is

$$
I=\sum_{k=1}^{n} A_{k}
$$

where $A_{k}$ is the residue of the integrand at $x_{k}$, and $h\left(x_{k}\right)=0$. This expression can be evaluated in terms of the coefficients $g_{k}$ and $a_{k}$ by starting with the obvious identity

$$
\frac{g(x)}{h(x) h(-x)} \equiv \sum_{k=1}^{n} A_{k}\left(\frac{1}{x-x_{k}}-\frac{1}{x+x_{k}}\right)
$$

Clearing fractions gives

$$
g(x) \equiv \sum_{k=1}^{n} A_{k}\left[\frac{h(x)}{x-x_{k}} h(-x)+\frac{h(-x)}{-x-x_{k}} h(x)\right]
$$

Since $x_{k}$ is a zero of $h(x)$, the quantity $h(x) /\left(x-x_{k}\right)$ is a polynomial; in fact,

$$
\frac{h(x)}{x-x_{k}}=\sum_{j=0}^{n-1} x^{n-1-j} \sum_{i=0}^{j} a_{i} x_{k}^{j-i}
$$

Substitution in (3) gives an identity between two polynomials. Equating coefficients of like powers of $x$ gives a set of simultaneous, linear, algebraic equations for the $A_{k}$ : 
(4)

$$
\sum_{k=1}^{n} \alpha_{l k} A_{k}=(-1)^{n} g_{l} / 2
$$

$$
(l=1,2, \cdots, n),
$$

where

$$
\begin{array}{ll}
\alpha_{l k}=\sum_{i=1}^{n} b_{l i} x_{k}^{i-1} & (l, k=1,2, \cdots n), \\
b_{l i}=\sum_{j=1}^{n} c_{l j} d_{j i} & (l, i=1,2, \cdots n), \\
c_{l j}=a_{2 l-j} & (l, j=1,2, \cdots, n), \\
d_{j i}=(-1)^{j} a_{j-i} & (j, i=1,2, \cdots, n),
\end{array}
$$

with the convention that $a_{k}=0$ if $k<0$ or $k>n$. With $\left|\alpha_{l k}\right|$ for the determinant with $n$ rows and $n$ columns having $\alpha_{l k}$ in the $l$ th row and $k$ th column, the rule for multiplying determinants $[1$, Chap. 8$]$ gives

$$
\left|\alpha_{l k}\right|=\left|c_{l j}\right| \cdot\left|d_{j i}\right| \cdot\left|x_{k}^{i-1}\right| \cdot
$$

Now,

$$
\left|d_{j i}\right|=\left|\begin{array}{ccccc}
-a_{0} & 0 & 0 & \cdots & 0 \\
a_{1} & a_{0} & 0 & \cdots & 0 \\
-a_{2} & -a_{1} & -a_{0} & \cdots & 0 \\
\cdot & \cdot & \cdot & \cdots & \cdot \\
\cdot & \cdot & \cdot & \cdots & \cdot \\
\pm a_{n-1} & \pm a_{n-2} & \pm a_{n-3} & \cdots & \pm a_{0}
\end{array}\right|=(-1)^{n(n+1) / 2} a_{0}^{n}
$$

and

$$
x_{k}^{i-1}=\left|\begin{array}{llll}
1 & 1 & \cdots & 1 \\
x_{1} & x_{2} & \cdots & x_{n} \\
x_{1}^{2} & x_{2}^{2} & \cdots & x_{n}^{2} \\
\cdot & \cdot & \cdots & \cdot \\
\cdot & \cdot & \cdots & \cdot \\
x^{n-1} & x_{2}^{n-1} & \ldots & x_{n}^{n-1}
\end{array}\right| \equiv V_{n},
$$


where $V_{n}$ is the well-known Vandermonde determinant.

Hence, writing $C_{n} \equiv\left|c_{l j}\right|$, we have

$$
\left|\alpha_{l k}\right|=(-1)^{n(n+1) / 2} a_{0}^{n} C_{n} V_{n},
$$

In equation (4), write $\beta_{l}=(-1)^{n} g_{l} / 2$ for convenience, and subtract $\beta_{l} l$ from both sides. Recalling equation $(2)$, we see that the resulting system can be put in the form

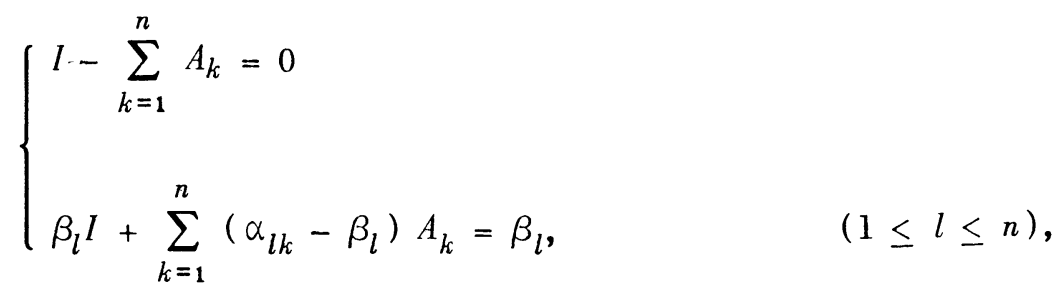

a system of $n+1$ equations in the $n+1$ unknowns $I, A_{1}, A_{2}, \cdots, A_{n}$ that can be solved directly for $l$. First consider thedeterminant, $D$, of the coefficients in the left members of $(5)$ :

$$
D=\left|\begin{array}{cccc}
1 & -1 & \cdots & -1 \\
\beta_{1} & \alpha_{11}-\beta_{1} & \cdots & \alpha_{1 n}-\beta_{1} \\
\beta_{2} & \alpha_{21}-\beta_{2} & \cdots & \alpha_{2 n}-\beta_{2} \\
\cdot & \cdot & \cdots & \cdot \\
\cdot & \cdot & \cdots & \cdot \\
\beta_{n} & \alpha_{n 1}-\beta_{n} & \cdots & \alpha_{n n}-\beta_{n}
\end{array}\right| .
$$

Adding the first column to each of the succeeding columns immediately gives the result

$$
\text { - } \quad D=\left|\alpha_{i j}\right|=(-1)^{n(n+1) / 2} a_{0}^{n} C_{n} V_{n} \text {. }
$$

Now $V_{n} \neq 0$, since all the zeros, $x_{k}$, of $h(x)$ were assumed to be distinct; and $C_{n}$ does not vanish, since it is precisely the Hurwitz determinant [2, p. 163] of the polynomial $h(x)$, all the roots of which lie in the left half-plane. Hence $D \neq 0$, and the system $(5)$ can be solved for $I$ directly by Cramer's rule [ 1 , Chap. 8] 


$$
D I=\left|\begin{array}{cccc}
0 & -1 & \cdots & -1 \\
\beta_{1} & \alpha_{11}-\beta_{1} & \cdots & \alpha_{1 n}-\beta_{1} \\
\beta_{2} & \alpha_{21}-\beta_{2} & \cdots & \alpha_{2 n}-\beta_{2} \\
\cdot & \cdot & \cdots & \cdot \\
\cdot & \cdot & \cdots & \cdot \\
\beta_{n} & \alpha_{n 1}-\beta_{n} & \cdots & \alpha_{n n}-\beta_{n}
\end{array}\right| .
$$

Again adding the first column to each succeeding column gives

$$
D I=\left|\begin{array}{cccc}
0 & -1 & \cdots & -1 \\
\beta_{1} & \alpha_{11} & \cdots & \alpha_{1 n} \\
\beta_{2} & \alpha_{21} & \cdots & \alpha_{2 n} \\
\cdot & \cdots & \cdots & \cdot \\
\beta_{n} & \alpha_{n 1} & \cdots & \alpha_{n n}
\end{array}\right|
$$

By the definition of $\alpha_{i j}$, this can be factored twice to give

$$
D I=\frac{M}{a_{0}}\left|\begin{array}{ccccc}
0 & 1 & 0 & \ldots & 0 \\
\beta_{1} & C_{11} & C_{12} & \ldots & C_{1 n} \\
\beta_{2} & C_{21} & C_{22} & \ldots & C_{2 n} \\
\bullet & \bullet & \bullet & \ldots & \bullet \\
\beta_{n} & C_{n 1} & C_{n 2} & \ldots & C_{n n}
\end{array}\right|,
$$

where

$$
M=\left|\begin{array}{cccc}
1 & 0 & \cdots & 0 \\
0 & d_{11} & \cdots & d_{1 n} \\
0 & d_{21} & \cdots & d_{2 n} \\
\cdot & \cdot & \cdots & \cdot \\
\cdot & \cdot & \cdots & \cdot \\
0 & d_{n 1} & \cdots & d_{n n}
\end{array}\right| \cdot\left|\begin{array}{cccc}
1 & 0 & \cdots & 0 \\
0 & 1 & \cdots & 1 \\
0 & x_{1} & \cdots & x_{n} \\
\cdot & \cdots & \cdots & \cdot \\
\cdot & \cdots & \cdots & \cdot \\
0 & x_{1}^{n-1} & \cdots & x_{n}^{n-1}
\end{array}\right|
$$


Thus,

$$
(-1)^{n(n+1) / 2} a_{0}^{n} C_{n} V_{n} I=\frac{-1}{a_{0}}\left|\begin{array}{cccc}
\beta_{1} & C_{12} & \cdots & C_{1 n} \\
\beta_{2} & C_{22} & \cdots & C_{2 n} \\
\cdot & \cdot & \cdots & \cdot \\
\cdot & \cdot & \cdots & \cdot \\
\beta_{n} & C_{n_{2}} & \cdots & C_{n n}
\end{array}\right| \cdot(-1)^{n(n+1) / 2} a_{0}^{n} V_{n}
$$

The relation $\beta_{l}=(-1)^{n} g_{l} / 2$ gives, finally, the desired formula:

$$
I \equiv \frac{1}{2 \pi i} \int_{-\infty i}^{\infty i} \frac{g(x) d x}{h(x) h(-x)}=\frac{(-1)^{n+1}}{2 a_{0}} \cdot \frac{G_{n}}{C_{n}},
$$

where

$$
\begin{gathered}
G_{n}=\left|g_{i j}\right|, C_{n}=\left|c_{i j}\right| \\
c_{i j}=a_{2 i-j}, g_{i j}= \begin{cases}g_{i} & \text { if } j=1 \\
c_{i j} & \text { if } j>1,\end{cases}
\end{gathered}
$$

Since $I$ is a continuous function of the coefficients of $h(x)$, and hence of the zeros, equation $(6)$ remains true when two zeros coincide.

\section{REFERENCES}

1. L. E. Dickson, First course in the theory of equations, John Wiley and Sons, Inc., New York, 1922.

2. P. Frank, and R.von Mises, Die Differential-und Integralgleichungen der Mechanik und Physik, Mary S. Rosenberg, 1943.

3. H. M. James, N. B. Nichols, and R. S. Phillips, Theory of servomechanisms, McGraw-Hill Book Company, Inc., New York, 1946.

4. E. T. Whittaker, and G. N. Watson, A course of modern analysis, Cambridge University Press, Fourth Edition, 1940.

National Advisory Committee for Aeronautics, Ames Aeronautical Laboratory, Moffett Field, California 


\section{PACIFIC JOURNAL OF MATHEMATICS}

\section{EDITORS}

\section{R. M. RoBINSON \\ University of California Berkeley 4, California}

\author{
*R. P. Dilmorth \\ Califomia Institute of Technology \\ Pasadena 4, California
}

E. F. BeckenbaCh, Managing Editor

University of California

Los Angeles 24, California

${ }^{*}$ During the absence of Herbert Busemann in 1952.

\section{ASSOCIATE EDITORS}

$\begin{array}{llll}\text { R. P. DILWORTH } & \text { P. R. HALMOS } & \text { BØRGE JESSEN } & \text { J. J. STOKER } \\ \text { HERBERT FEDERER } & \text { HEINZ HOPF } & \text { PAUL LÉVY } & \text { E. G. STRAUS } \\ \text { MARSHALL HALL } & \text { R. D. JAMES } & \text { GEORGE PÓLYA } & \text { KÖSAKU YOSIDA }\end{array}$

\section{SPONSORS}

UNIVERSITY OF BRITISH COLUMBIA

CALIFORNIA INSTITUTE OF TECHNOLOGY

UNIVERSITY OF CALIFORNIA, BERKELEY

UNIVERSITY OF CALIFORNIA, DAVIS

UNIVERSITY OF CALIFORNIA, LOS ANGELES

UNIVERSITY OF CALIFORNIA, SANTA BARBARA

OREGON STATE COLLEGE

UNIVERSITY OF OREGON

\author{
UNIVERSITY OF SOUTHERN CALIFORNIA \\ STANFORD UNIVERSITY \\ WASHINGTON STATE COLLEGE \\ UNIVERSITY OF WASHINGTON \\ AMERICAN MATHEMATICAL SOCIETY \\ NATIONAL BUREAU OF STANDARDS, \\ INSTITUTE FOR NUMERICAL ANALYSIS
}

Mathematical papers intended for publication in the Pacific Journal of Miathematics should be typewritten (double spaced), and the author should keep a complete copy. Manuscripts may be sent to any of the editors. All other communications to the editors should be addressed to the managing editor, E. F. Beckenbach, at the address given above.

Authors are entitled to receive 100 free reprints of their published papers and may obtain additional copies at cost.

The Pacific Journal of Mathematics is published quarterly, in March, June, September, and December, by the University of California, Berkeley 4, California. The price per volume (4 numbers) is \$8.00; single issues, $\$ 2.50$. Special price to individual faculty members of supporting institutions and to individual members of the American Mathematical Society: $\$ 4.00$ per volume; single issues, $\$ 1.25$.

Subscriptions, orders for back numbers, and changes of address should be sent to the publishers, University of California Press, Berkeley 4, California.

Printed at Ann Arbor, Michigan. Entered as second class matter at the Post Office, Berkeley, California.

\section{UNIVERSITY OF CALIFORNIA PRESS • BERKELEY AND LOS ANGELES}




\section{Pacific Journal of Mathematics}

\section{Vol. 2, No. $4 \quad$ April, 1952}

Shmuel Agmon, On the singularities of Taylor series with reciprocal coefficients .................................... 431

Richard Arens, A generalization of normed rings ............... 455

Iacopo Barsotti, Intersection theory for cycles of an algebraic variety . . . . 473

Leonard M. Blumenthal, Two existence theorems for systems of linear inequalities ..................................... 523

Frank Herbert Brownell, III, Translation invariant measure over separable Hilbert space and other translation spaces................. 531

J. W. S. Cassels, On a paper of Niven and Zuckerman ............... 555

Nelson Dunford, Spectral theory. II. Resolutions of the identity .......... 559

Eugene Lukacs and Otto Szász, On analytic characteristic functions ...... 615

W. A. Mersman, Evaluation of an integral occurring in servomechanism theory.......................................... 627

Lawrence Edward Payne and Alexander Weinstein, Capacity, virtual mass, and generalized symmetrization......................... 633

Choy-Tak Taam, The boundedness of the solutions of a differential equation in the complex domain ...................................... 643 